\title{
Electrochemical Characterization of Thin Passive Films on Nb Electrodes in $\mathrm{H}_{3} \mathrm{PO}_{4}$ Solutions
}

\author{
Sonia R. Biaggio ${ }^{a}$, Nerilso Bocchi ${ }^{a}$, Romeu C. Rocha-Filho ${ }^{{ }^{*}}$, \\ and Francisco E. Varela ${ }^{b}$ \\ ${ }^{a}$ Departamento de Química, Universidade Federal de São Carlos, C.P. 676, \\ 13560-970 São Carlos - SP, Brazil \\ ${ }^{b}$ Instituto de Investigaciones Fisicoquímicas Teóricas y Aplicadas (INIFTA), Facultad \\ de Ciencias Exactas, Universidad Nacional de La Plata, Sucursal 4, \\ Casilla de Correo 16, (1900) La Plata, Argentina
}

Received: April 7, 1997; July 30, 1997

The electrical and semiconducting properties of thin anodic passive films potentiostatically formed $\left(1 \mathrm{~V} \leq E_{\mathrm{f}} \leq 5 \mathrm{~V} v s\right.$. sce $)$ on polycrystalline niobium electrodes in aqueous $0.5 \mathrm{~mol} / \mathrm{L} \mathrm{H}_{3} \mathrm{PO}_{4}$ solutions ( $\mathrm{pH}$ 1.3) were studied, at room temperature, using electrochemical impedance spectroscopy. The data were analysed with a transfer function using a non-linear fitting routine, assuming that the resistance of the film is coupled in series with the faradaic impedance of the $\mathrm{Nb}(0) \rightarrow \mathrm{Nb}(\mathrm{V})$ reaction, and these in parallel with the capacitance of the passive film/electrolyte interface. The relative permittivity of the films was estimated as about 44 . The number concentration of donors $\left(N_{\mathrm{D}}\right)$ in the films was found to decrease with $E_{\mathrm{f}}$ (i.e., with increasing film thickness). A flat band potential value of $-0.72 \mathrm{~V}$ was also obtained from Mott-Schottky plots.

Utilizando-se a espectroscopia de impedância eletroquímica, foram estudadas as propriedades elétricas e semicondutoras de filmes anódicos passivos formados potenciostaticamente $\left(1 \mathrm{~V} \leq E_{\mathrm{f}} \leq\right.$ $5 \mathrm{~V} v$ s. ecs) sobre eletrodos de nióbio policristalino em soluções aquosas de $\mathrm{H}_{3} \mathrm{PO}_{4} 0,5 \mathrm{~mol} / \mathrm{L}$ ( $\mathrm{pH}$ $1,3)$, a temperatura ambiente. Os dados foram analisados com uma função de transferência usando uma rotina de ajuste não-linear, supondo que a resistência do filme está acoplada em série com a impedância faradaica da reação $\mathrm{Nb}(0) \rightarrow \mathrm{Nb}(\mathrm{V})$ e estas em paralelo com a capacitância da interface filme/eletrólito. A permissividade relativa dos filmes foi estimada como cerca de 44. Encontrou-se que a concentração em número de doadores $\left(N_{\mathrm{D}}\right)$ nos filmes decresce com $E_{\mathrm{f}}$ (isto é, à medida que a espessura do filme aumenta). A partir de gráficos de Mott-Schottky, também obteve-se um valor de $-0,72 \mathrm{~V}$ para o potencial de banda plana.

Keywords: niobium, anodic oxide, semiconducting properties, potentiostatic growth, impedance spectroscopy

\section{Introduction}

Being a valve metal, niobium passivates with a high corrosion resistance in most common aqueous media ${ }^{1-4}$. The passive films, constituted of amorphous niobium pentoxide ${ }^{3}$, can be easily thickened by anodic polarisation ${ }^{3-7}$; the oxide growth occurs by high-field ion migration in the film $^{8,9}$. Amorphous niobium pentoxide has a density ${ }^{10}$ of $4.74 \mathrm{~g} \mathrm{~cm}^{-3}$ and a rather high concentration of oxygen vacancies $\left(10^{19}\right.$ $\mathrm{cm}^{-3}$ ) that, injected at the metal/oxide interface, act as donor states and make the oxide an $n$-type semiconductor ${ }^{11,12}$; Di Quarto et al. ${ }^{4}$, studying films of various thickness $(21 \mathrm{~nm} \leq d$ $\leq 210 \mathrm{~nm}$ ) formed in $0.5 \mathrm{~mol} / \mathrm{L} \mathrm{H}_{2} \mathrm{SO}_{4}$, determined their relative permittivity as being equal to 42 . Niobium pentoxide crystals have a band gap of $3.4 \mathrm{eV}^{13}$.

Although anodic films of niobium have been quite extensively studied (most of the data in the literature are for 
high-voltage anodised niobium), there is no report in the literature of a systematic study of the impedance behaviour of thin films $(<20 \mathrm{~nm})$. Recently we have investigated the electrical and semiconducting properties of thin anodic films of tungsten ${ }^{14,15}$, zirconium ${ }^{16}$ and tin-indium alloys ${ }^{17,18}$. Herein we are extending these systematic investigations to niobium; thus, the main purpose of this work was to characterise the electrochemical behaviour and electrical properties of thin anodic passive films potentiostatically formed on niobium in aqueous $0.5 \mathrm{~mol} / \mathrm{L} \mathrm{H}_{3} \mathrm{PO}_{4}$ solutions, using electrochemical impedance spectroscopy. The influence of film thickness on the semiconducting properties of the thin films was investigated.

\section{Experimental}

Polycrystalline niobium rods $(99.98 \%$ purity, $0.70 \mathrm{~cm}$ diameter) included in epoxy resin were used as working electrodes. Prior to each experiment, the electrodes were mechanically polished down to 600 grit silicon carbide paper. The counter electrode was a cylindrical platinum grid placed around the working electrode. A saturated calomel electrode (sce), coupled to a Luggin probe, was used as reference for all potential measurements. The experiments were carried out at room temperature $\left(25^{\circ} \mathrm{C}\right)$ in

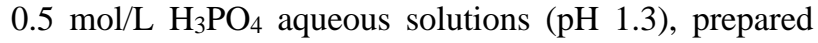
from AR grade chemicals and purged with $\mathrm{N}_{2}$ prior and during each experiment.

In order to characterise different redox processes occurring on the niobium electrode, triangular potential scans were performed between preset cathodic $\left(E_{\mathrm{s}, \mathrm{c}}\right)$ and anodic $\left(E_{\mathrm{s}, \mathrm{a}}\right)$ switching potentials at different scan rates $v$, using an Eco Chemie Autolab/GPES potentiostat/galvanostat system.

The impedance behavior study was done on thin $\mathrm{Nb}_{2} \mathrm{O}_{5}$ films potentiostatically grown. This gowth was carried out at a given formation potential $\left(E_{\mathrm{f}}\right)$ until steady-state currents were reached, usually after $c a$. $1 \mathrm{~h} ; E_{\mathrm{f}}$ was set between $1 \mathrm{~V}$ and $5 \mathrm{~V}$ (vs. sce). For each film, electrochemical impedance data were acquired in the $5 \mathrm{mHz} \leq f \leq 10 \mathrm{kHz}$ frequency range, at $E_{\mathrm{f}}$; an rms AC signal modulation of $30 \mathrm{mV}$ was used. In order to obtain data to analyse the semiconducting properties of the films, high-frequency impedance data $(100 \mathrm{~Hz} \leq f \leq 10 \mathrm{kHz})$ were acquired at several potentials increasingly more negative than $E_{\mathrm{f}}$. An Eco Chemie frequency response analyser module, coupled to the Autolab/GPES potentiostat/galvanostat system, was used to perform all the impedance measurements.

\section{Results and Discussion}

\section{Voltammetric data}

A voltammogram of $\mathrm{Nb}$ in $0.5 \mathrm{~mol} / \mathrm{L} \mathrm{H}_{3} \mathrm{PO}_{4}$ obtained between $E_{\mathrm{s}, \mathrm{c}}=-0.8 \mathrm{~V}$ and $E_{\mathrm{s}, \mathrm{a}}=5 \mathrm{~V}(v s$. sce $)$ at $v=20 \mathrm{mV}$ $\mathrm{s}^{-1}$ is shown in Fig. 1. The positive-going potential scan exhibits a well-defined anodic current peak (A1) at about $-0.20 \mathrm{~V}$, followed by a wide passive potential region that is characteristic of the growth of anodic films on valve metals. The voltammogram also exhibits a step-wise increase of the anodic current when the electrode potential is $c a .1 .8$ $\mathrm{V}$; this increase was previously reported by Di Quarto et $a l .{ }^{12}$ for voltammograms obtained on niobium in sulphuric acid solutions and was tentatively assigned to the onset of oxygen evolution. No significant oxygen evolution was noticed, however; further studies in several acid solutions are now in progress in order to better characterise this oxidation process ${ }^{19}$. As the voltammetric scan is reversed, the current decreases sharply and no cathodic current contributions corresponding to the electroreduction of surface oxides are observed; at about $-0.6 \mathrm{~V}$, hydrogen evolution begins.

Although a detailed analysis of the voltammogrammes is out of the scope of this paper, chemical and thermodynamic considerations add information supporting that peak A1 is related to the oxidation of the electrode surface to $\mathrm{Nb}_{2} \mathrm{O}_{5}{ }^{1,20-22}$. It is important to mention, however, that the peak A1 potential, $-0.20 \mathrm{~V}$, differs considerably from -0.97 $\mathrm{V}$ corresponding to the $\mathrm{Nb} / \mathrm{Nb}_{2} \mathrm{O}_{5}$ reversible electrode potential $^{20}$. The latter potential was estimated from standard Gibbs energy data of both products and reactants for the oxidation of $\mathrm{Nb}$ at $\mathrm{pH}$ 1.3. The tendency of niobium to form very stable oxygen compounds ${ }^{1,20}$ strongly suggests that, during the surface preparation, an irreversible oxidation process occurs at the electrode surface involving niobium suboxides $^{12}$. Moreover, the detection of a surface film formed before anodisation was reported by several authors ${ }^{4,12,21,22}$; Di Quarto et al. ${ }^{4}$ estimated the thickness of this pre-film as being about $4 \mathrm{~nm}$. Thus, the presence of this previously formed film might determine a shift of the electrode oxidation potential to a value more positive than that for the $\mathrm{Nb} / \mathrm{Nb}_{2} \mathrm{O}_{5}$ reversible process.

\section{Electrochemical impedance data}

The impedance profile of the passivated $\mathrm{Nb}$ electrodes was found to depend on both $E_{\mathrm{f}}$ and the operational potential $\left(E<E_{\mathrm{f}}\right)$ at which the impedance spectra were obtained. Typical complex-plane and Bode plots obtained at different $E_{\mathrm{f}}$ values are shown in Fig. 2 . In the $10 \mathrm{mHz}-10 \mathrm{kHz}$

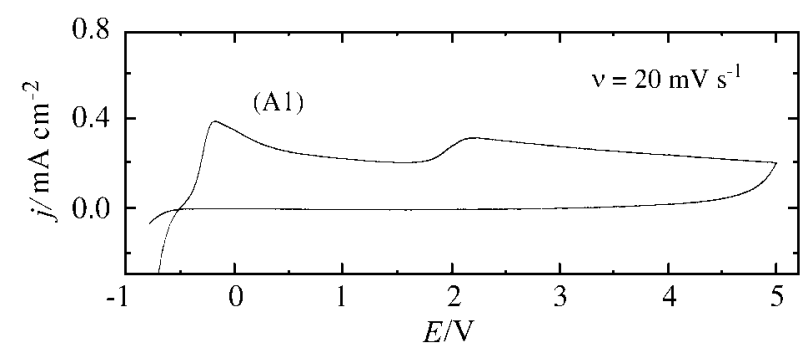

Figure 1. Voltammogram of $\mathrm{Nb}$ in $0.5 \mathrm{~mol} / \mathrm{L} \mathrm{H}_{3} \mathrm{PO}_{4}(\mathrm{pH} 1.3$ ) obtained between $E_{\mathrm{s}, \mathrm{c}}=-0.8 \mathrm{~V}$ and $E_{\mathrm{s}, \mathrm{a}}=5 \mathrm{~V}(v s$. sce $)$ at $v=0.02 \mathrm{~V} \mathrm{~s}^{-1}$. 


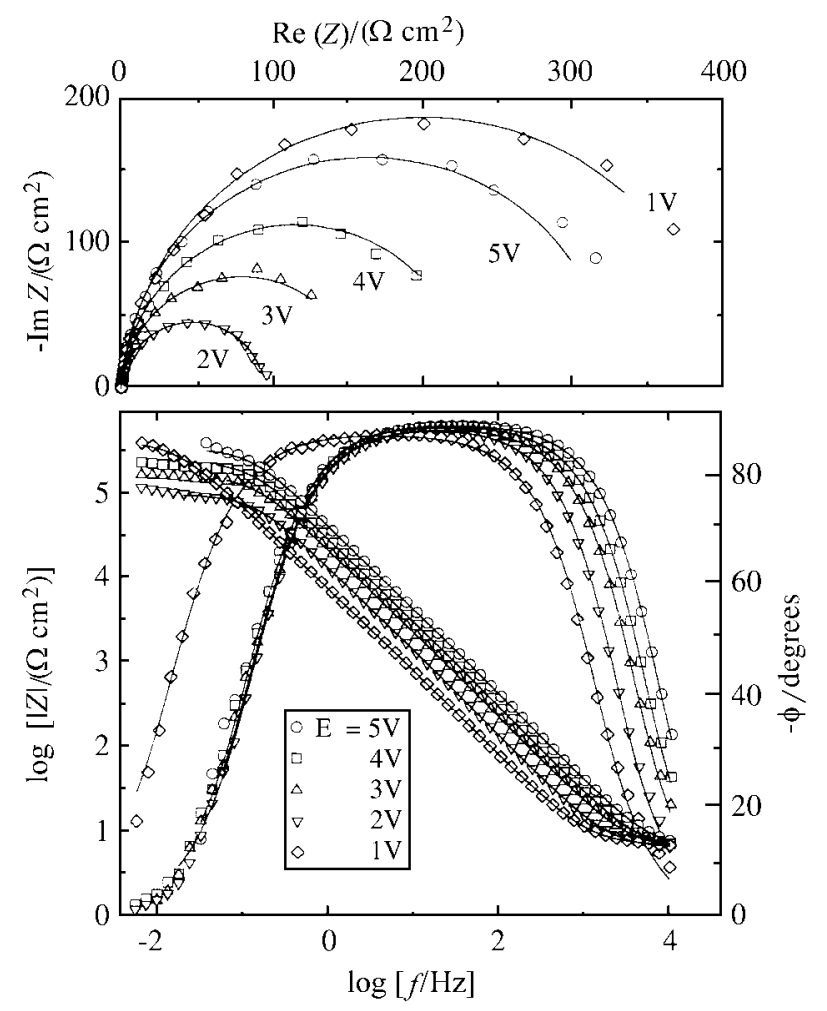

Figure 2. Complex-plane and Bode plots obtained for thin anodic $\mathrm{Nb}_{2} \mathrm{O}_{5}$ films formed on $\mathrm{Nb}$ electrodes at different formation potentials $E_{\mathrm{f}}(v s . s c e)$ in $0.5 \mathrm{~mol} / \mathrm{L} \mathrm{H}_{3} \mathrm{PO}_{4}$ ( $\mathrm{pH} 1.3$ ). The lines correspond to calculated impedance data according to a transfer function (see text).

frequency range, only one capacitive semicircle is present for all $E_{\mathrm{f}}$ values. The corrosion resistance, defined as $R_{\mathrm{p}}=$ $\lim _{\omega \rightarrow 0}[Z(j \omega)]$, becomes smaller as $E_{\mathrm{f}}$ is decreased from 5 $\mathrm{V}$ to $2 \mathrm{~V}$ and then becomes larger for $E_{\mathrm{f}}=1 \mathrm{~V}$. These variations in the value of $R_{\mathrm{p}}$ are in agreement with the voltammetric profile shown in Fig. 1, in which a step-wise variation in the anodic current was observed at about $1.8 \mathrm{~V}$.

As pointed out by Bai and Conway ${ }^{23}$, a detailed transfer function interpreting the whole impedance spectra cannot be elucidated by means of steady-state techniques alone, especially when the electrode process involves a multielectron transfer process such as $\mathrm{Nb}(0) \rightarrow \mathrm{Nb}(\mathrm{V})$, since information about intermediate reaction steps is not available. However, impedance data are diagnostically useful, as they can provide a variety of information, in particular on the main reactions contributing to the faradaic current at the reacting interface and on the electrical characteristics of the anodic films on the metal electrode ${ }^{14-18}$.

An appropriate transfer function interpreting the complete set of experimental data, in the $1 \mathrm{~V} \leq E_{\mathrm{f}} \leq 5 \mathrm{~V}$ potential range, should include the resistance of the passive film $\left(R_{\mathrm{ox}}\right)$ in series with the faradaic impedance of the $\mathrm{Nb}(0)$ $\rightarrow \mathrm{Nb}(\mathrm{V})$ oxidation process represented by the charge transfer resistance of the process $\left(R_{\mathrm{ct}}\right)$, and these in parallel with the capacitance $(C)$ of the metal/passive film/electro- lyte system. Thus, the impedance spectra will be discussed according to the following transfer function:

$$
\mathrm{Z}(\mathrm{j} \omega)=R_{\Omega}+\frac{R_{\mathrm{ox}}+R_{\mathrm{ct}}}{1+\mathrm{j} \omega C\left(R_{\mathrm{ox}}+R_{\mathrm{ct}}\right)}
$$

where $\omega$ is the angular frequency $(2 \pi f)$, and the high-frequency limit, $R_{\Omega}$, is the ohmic resistance of the electrolyte. Unfortunately, resistances $R_{\mathrm{ct}}$ and $R_{\mathrm{ox}}$ are in series in Eq. 1 and, consequently, cannot be determined separately. However, since $R_{\mathrm{ct}}<R_{\mathrm{ox}}$ for this case, one can assume that the value of $R_{\mathrm{ox}}$ is directly accessible through the fitting procedure and that the value of $R_{\mathrm{ct}}$ is, thus, inaccessible. The experimental spectra are satisfactorily described by transfer function (1) if an appropriate choice of parameters is made; the theoretical functions obtained from the parameters fitted with a complex non-linear least-squares algorithm are depicted as continuous lines in Fig. 2. The values obtained for the different parameters at the potentials $E_{\mathrm{f}}$ are shown in Table 1. As can be seen from this table, the value of $C$ decreases with increasing $E_{\mathrm{f}}$; this capacitance can be seen as a series combination of the oxide $\left(C_{\mathrm{ox}}\right)$ and the Helmholtz layer capacitances $\left(C_{\mathrm{H}}\right)$, i.e.:

$$
\frac{1}{C}=\frac{1}{C_{\mathrm{ox}}}+\frac{1}{C_{\mathrm{H}}}
$$

The values of $C_{\text {ox }}$ were obtained through Eq. 2 , assuming a conservative constant value of $20 \mu \mathrm{F} \mathrm{cm}^{-2}$ for $C_{\mathrm{H}}$. Figure 3 shows that the relationship between $C_{\mathrm{ox}}{ }^{-1}$ and $E_{\mathrm{f}}$ is linear; consequently, $C_{\mathrm{ox}}$ can be directly correlated with the thickness $d$ of the passive film using the formula for a parallel plane condenser:

$$
C_{\mathrm{ox}}=\frac{\varepsilon_{\mathrm{r}} \varepsilon_{0}}{d}
$$

where $\varepsilon_{\mathrm{r}}$ denotes the relative permittivity of the film and $\varepsilon_{\mathrm{o}}$ the permittivity of vacuum. Di Quarto et al. ${ }^{4}$ determined by optical methods that the thickness $d$ of anodically grown $\mathrm{Nb}_{2} \mathrm{O}_{5}$ films increases linearly with the applied formation potential $E_{\mathrm{f}}$, i.e.:

$$
d=\alpha\left(E_{\mathrm{f}}-E^{0}\right)
$$

where $E^{\circ}$ is the potential at which the film starts to grow and $\alpha$ is the anodising ratio.

From eqs. 3 and 4 one obtains

$$
\frac{1}{C_{\mathrm{ox}}}=\frac{\alpha}{\varepsilon_{\mathrm{r}} \varepsilon_{0}}\left(E_{\mathrm{f}}-\mathrm{E}^{0}\right)
$$

If an average anodising ratio $\alpha$ of $2.2 \mathrm{~nm} \mathrm{~V}^{-1}$ is assumed $^{4}$, the relative permittivity of the thin passive films can be estimated from the slope of the $C_{\mathrm{ox}}{ }^{-1} v s . E_{\mathrm{f}}$ plot shown in Fig. 3 as being about 44. This value agrees quite well with the one previously reported by Di Quarto et al. ${ }^{4}$ 


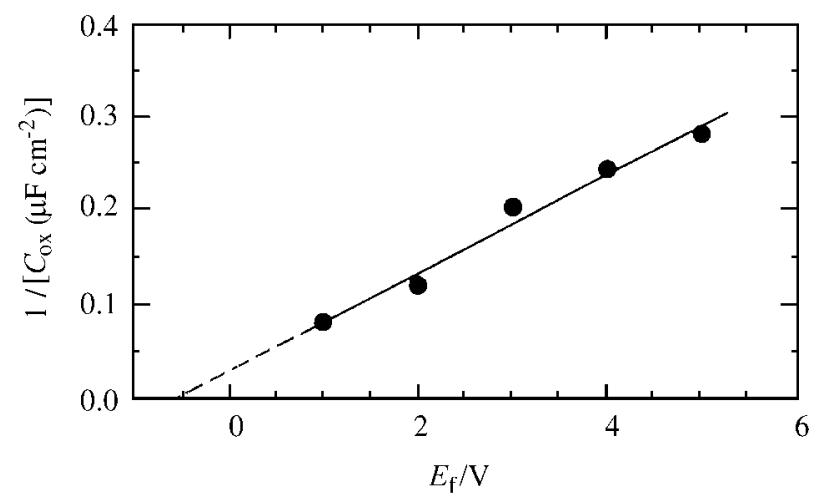

Figure 3. Inverse of the oxide capacitance $C_{\mathrm{ox}}$ as a function of the formation potential $E_{\mathrm{f}}$ ( $v s$. sce), for thin anodic $\mathrm{Nb}_{2} \mathrm{O}_{5}$ films formed on $\mathrm{Nb}$ electrodes in $0.5 \mathrm{~mol} / \mathrm{L} \mathrm{H}_{3} \mathrm{PO}_{4}(\mathrm{pH} 1.3)$.

$\left(\varepsilon_{\mathrm{r}}=42\right)$ for thicker films grown galvanostatically in sulphuric acid solutions. Finally, the estimation of $E^{\circ}$ from Fig. 3 (see Eq. 5) yields a value close to $-0.55 \mathrm{~V}$, a value more cathodic than the potential corresponding to anodic peak A1 observed in the voltammograms and consistent with the zero-current potential obtained for niobium in this electrolyte (see Fig. 1).

The values of $R_{\mathrm{ox}}$ obtained for the different formation potentials are also shown in Table 1 . They increase with $E_{\mathrm{f}}$, except for the value obtained at $E_{\mathrm{f}}=1 \mathrm{~V}$, which is exceptionally high. As pointed out above, for potentials greater than $1.8 \mathrm{~V}$ an additional contribution to the anodic current appears in the voltammograms of $\mathrm{Nb}$ in $\mathrm{H}_{3} \mathrm{PO}_{4}$. The significant decrease in the value of $R_{\mathrm{ox}}$ when $E_{\mathrm{f}}$ is varied from $1 \mathrm{~V}$ to $2 \mathrm{~V}$ indicates that the properties of the passivating film greatly change; as mentioned before, this matter is being further studied. For $2 \mathrm{~V} \leq E_{\mathrm{f}} \leq 5 \mathrm{~V}, R_{\mathrm{ox}}$ steadily increases, reflecting the increasing film thickness.

It is expected that for a passive layer grown at a certain $E_{\mathrm{f}}$, the faradaic reaction associated with the formation of the film should decrease if the electrode operational potential is shifted to a value $E<E_{\mathrm{f}}$. As pointed out previously ${ }^{15}$, this happens because the faradaic reaction decreases sharply for fields lower than the film formation field. Thus,

Table 1. Dependence of the value of the transfer function parameters $R_{\Omega}$, $R_{\mathrm{ox}}$ and $C$ on the formation potential $E_{\mathrm{f}}$ (vs. sce), for thin anodic $\mathrm{Nb}_{2} \mathrm{O}_{5}$ films formed on $\mathrm{Nb}$ electrodes in $0.5 \mathrm{~mol} / \mathrm{L} \mathrm{H}_{3} \mathrm{PO}_{4}(\mathrm{pH} 1.3)$. These values were obtained by fitting the transfer function to the data shown in Fig. 2 with a complex non-linear least-squares algorithm (see text).

\begin{tabular}{lccc}
\hline$E_{\mathrm{f}} / \mathrm{V}$ & $R_{\Omega} / \Omega \mathrm{cm}^{2}$ & $R_{\mathrm{OX}} / \mathrm{k} \Omega \mathrm{cm}^{2}$ & $C / \mathrm{mF} \mathrm{cm}^{-2}$ \\
\hline 1 & 7.9 & 400 & 16.9 \\
2 & 7.4 & 95 & 10.3 \\
3 & 7.4 & 160 & 6.3 \\
4 & 7.3 & 233 & 4.8 \\
5 & 7.3 & 330 & 3.4 \\
\hline
\end{tabular}

from impedance spectra obtained at $E<E_{\mathrm{f}}$, the values of $C$ decrease with increasing $E$ (see Fig. 4) until they become nearly constant at potentials close to $E_{\mathrm{f}}$. This constant value, which was found to be dependent on the film thickness, i.e., $E_{\mathrm{f}}$, coincides with the value of $C$ obtained from the whole impedance spectra at $E_{\mathrm{f}}$ fitted with Eq. 1 . The change in the value of $C$ with $E$ can be explained by assuming that the passive layers formed on niobium behave as non-stoichiometric semiconducting films. Taking into account the large band gap of $\mathrm{Nb}_{2} \mathrm{O}_{5}$ films $(3.4 \mathrm{eV})$, large anodic polarisations induce space charge layers that encompass the whole film, leading to a constant capacitance, whose value reflects both the thickness and the relative permittivity of the film according to Eq. 3. Then, the whole thin film is in deep depleted conditions, with surface charges at both the oxide/solution and the metal/oxide interfaces ${ }^{13-15}$, and $C_{\mathrm{ox}}$ is the capacitance available. On the other hand, at the lower operational potentials, $C$ can be assumed as corresponding to the space charge capacitance $\left(C_{\mathrm{sc}}\right)$ of the semiconductor $\mathrm{Nb}_{2} \mathrm{O}_{5}$ film in the depleted region, after taking into account the value of $C_{\mathrm{H}}(20 \mu \mathrm{F}$ $\mathrm{cm}^{-2}$ ). Hence, for the films grown at different $E_{\mathrm{f}}, C$ increases as $E_{\mathrm{f}}$ becomes less positive (Fig. 4).

The Mott-Schottky plots $\left(C_{\mathrm{sc}}{ }^{-2} v\right.$ v. E) for the $\mathrm{Nb}_{2} \mathrm{O}_{5}$ films formed in $\mathrm{H}_{3} \mathrm{PO}_{4}$ are shown in Fig. 5. From these results, which clearly characterise an $n$-type semiconductor behaviour of the oxide film, it is possible to determine the number concentration of donors $\left(N_{\mathrm{D}}\right)$ in the space charge region as well as to estimate the flat band potential $\left(E_{\mathrm{FB}}\right)$ for the films grown at each anodic potential. This was done using the above calculated value of the relative permittivity of the $\mathrm{Nb}_{2} \mathrm{O}_{5}$ films formed in $\mathrm{H}_{3} \mathrm{PO}_{4}$ and the well-known Mott-Schottky relationship:

$$
C_{\mathrm{sc}}^{-2}=\frac{2 N_{\mathrm{A}}}{N_{\mathrm{D}} F \varepsilon_{\mathrm{r}} \varepsilon_{0}}\left(E-E_{\mathrm{FB}}-\frac{R T}{F}\right)
$$

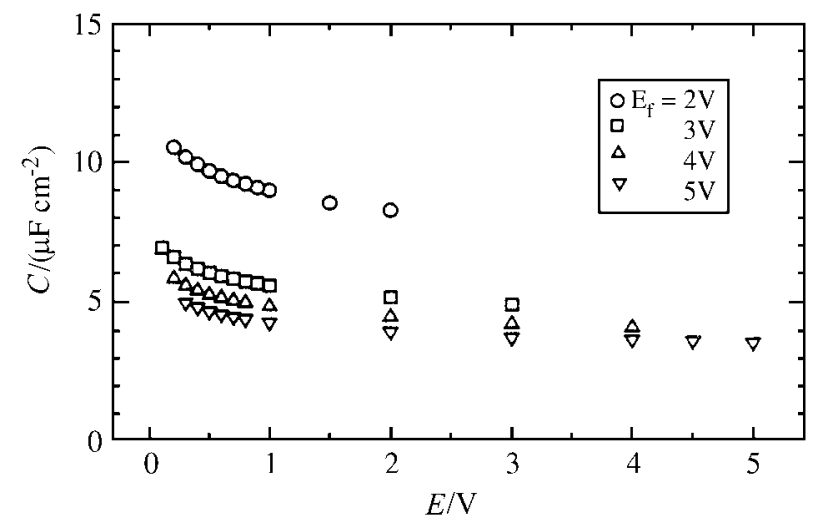

Figure 4. Capacitance of metal/passive film/electrolyte system as a function of the applied potential $E$ ( $v s$. sce), for thin anodic $\mathrm{Nb}_{2} \mathrm{O}_{5}$ films formed on $\mathrm{Nb}$ electrodes at different formation potentials $E_{\mathrm{f}}$ in $0.5 \mathrm{~mol} / \mathrm{L}$ $\mathrm{H}_{3} \mathrm{PO}_{4}(\mathrm{pH} 1.3)$. 


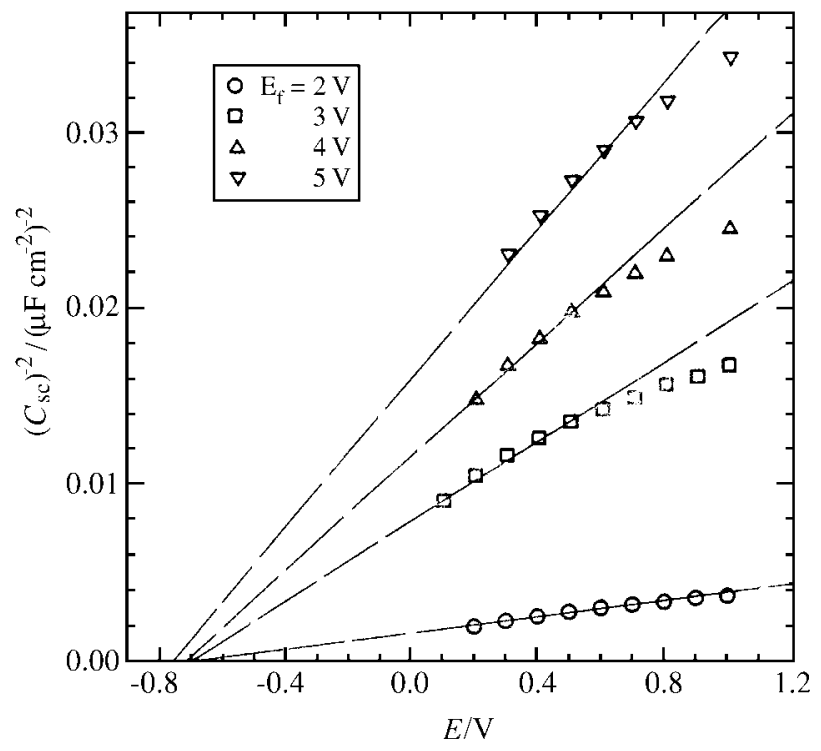

Figure 5. Mott-Schottky plots for thin anodic $\mathrm{Nb}_{2} \mathrm{O}_{5}$ films formed on $\mathrm{Nb}$ electrodes in $0.5 \mathrm{~mol} / \mathrm{L} \mathrm{H}_{3} \mathrm{PO}_{4}(\mathrm{pH} 1.3)$, at the indicated formation potentials $E_{\mathrm{f}}(v s . s c e)$.

where $N_{\mathrm{A}}$ is the Avogadro constant, $F$ the Faraday constant, $T$ the thermodynamic temperature and $R$ the molar gas constant.

As shown in Table $2, N_{\mathrm{D}}$ decreases with $E_{\mathrm{f}}$ (i.e., increasing film thickness), indicating that the average number concentration of donors becomes smaller as the film becomes thicker. This behaviour, which is similar to the one previously reported ${ }^{14,15}$ for thin $\mathrm{WO}_{3}$ films anodically grown on tungsten in several electrolytes, can be partially due to a higher contribution from the surface states on decreasing the film thickness. However, an influence of the thickness on the $N_{\mathrm{D}}$ value as a consequence of a higher defect concentration in thin films cannot be excluded. Nevertheless, the values obtained for $N_{\mathrm{D}}$ are consistently larger than the ones reported by Di Quarto et al. ${ }^{4}$ for thicker films.

From Fig. 5 and using Eq. 6, $E_{\mathrm{FB}}$ can be estimated as about $-0.72 \mathrm{~V}$. This value is somewhat more negative than the values previously reported for thicker $\mathrm{Nb}_{2} \mathrm{O}_{5}$ films galvanostatically grown on $\mathrm{Nb}$ electrodes in $0.5 \mathrm{~mol} / \mathrm{L}$

Table 2. Values of the donor number concentration $\left(N_{\mathrm{D}}\right)$ as a function of the formation potential $E_{\mathrm{f}}$ ( $v s$. sce), for thin $\mathrm{Nb}_{2} \mathrm{O}_{5}$ films anodically grown on $\mathrm{Nb}$ electrodes in $0.5 \mathrm{~mol} / \mathrm{L} \mathrm{H}_{3} \mathrm{PO}_{4}(\mathrm{pH} 1.3)$.

\begin{tabular}{lc}
\hline$E_{\mathrm{f}} / \mathrm{V}$ & $N_{\mathrm{D}} /\left(10^{20} \mathrm{~cm}^{-3}\right)$ \\
\hline 2 & 14 \\
3 & 2.8 \\
4 & 2.0 \\
5 & 1.5 \\
\hline
\end{tabular}

$\mathrm{H}_{2} \mathrm{SO}_{4}, E_{\mathrm{FB}} \approx 0.2 \mathrm{~V}(\text { vs. sce })^{4}$, and in $0.1 \mathrm{~mol} / \mathrm{L}$ oxalic acid, $E_{\mathrm{FB}} \approx-0.2 \mathrm{~V}(\text { vs. sce })^{24}$.

Although some doubts have been raised concerning the application of the Mott-Schottky theory to amorphous semiconductors ${ }^{4,11,25}$, the non-linearity of the $C_{\mathrm{sc}}{ }^{-2} v s . E$ plots at potentials far from the flat band potential is an expected fact for thin semiconducting films subjected to high electric fields. As mentioned above, for potentials far from $E_{\mathrm{FB}}$, the thickness of the space charge layer becomes equal to the film thickness, and the capacitance of the interface behaves according to Eq. 5 .

\section{Acknowledgments}

This work was made possible by grants from FAPESP - Fundação de Amparo à Pesquisa do Estado de São Paulo (Brazil), including a visiting-scientist fellowship to $\mathrm{F}$. E. Varela; support from CNPq - Conselho Nacional de Desenvolvimento Científico e Tecnológico (Brazil) is also gratefully acknowledged.

\section{References}

1. Udupa, H.V.K.; Venkatesan, V.K. In Encyclopedia of Electrochemistry of the Elements; Bard, A.J., Ed.; Marcel Dekker: New York, 1974; Vol. 2, Chapter 3.

2. D'Alkaine, C.V.; de Souza, L.M.M.; Nart, F.C. Corrosion Sci. 1993, 34, 109.

3. Young, L. Anodic Oxide Films; Academic Press: London, 1961.

4. Di Quarto, F.; Piazza, S.; Sunseri, C. Electrochim. Acta 1990, 35, 99.

5. Goruk, W.S.; Young, L.; Zobel, F.G.R. In Modern Aspects of Electrochemistry; Bockris, J.O'M., Ed.; Plenum Press: New York, 1966; Vol. 4, Chapter 3.

6. Gomez, M.A.B.; Onofre, S.; Juanto, S.; Bulhões, L.O.S. J. Appl. Electrochem. 1991, 21, 1023.

7.Hurlen, T.; Bentzen, H.; Hornkjøl, S. Electrochim. Acta 1987, 32, 1613.

8. Dignam, M.J. In Comprehensive Treatise of Electrochemistry; Bockris, J.O’M.; Conway, B.E.; Yeager, E.; White, R.E., Eds.; Plenum Press: New York, 1981; Vol. 4, Chapter 5.

9. Davies, J.A.; Domeij, B.; Pringle, J.P.S.; Brown, F. J. Electrochem. Soc. 1965, 112, 675.

10. Murti, D.K.; Kelly, R. Thin Solid Films 1976, 33, 149.

11. Di Quarto, F.; Sunseri, C.; Piazza, S. Ber. Bunsenges. Phys. Chem. 1986, 90, 549.

12. Di Quarto, F.; Piazza, S.; Sunseri, C. J. Chem. Soc., Faraday Trans. 1 1989, 85, 3309.

13. Morrison, S.R. Electrochemistry at Semiconductor and Oxidized Metal Electrodes; Plenum: New York, 1980; Chapter 2. 
14.Biaggio, S.R.; Rocha-Filho, R.C.; Vilche, J.R.; Varela, F.E.; Gassa, L.M. J. Braz. Chem. Soc. 1994, $5,123$.

15. Biaggio, S.R.; Rocha-Filho, R.C.; Vilche, J.R.; Varela, F.E.; Gassa, L.M. Electrochim. Acta 1997, 42, 1751.

16. Biaggio, S.R.; Bocchi, N.; Rocha-Filho, R.C.; Tanzella, F.L., in preparation.

17. Ybarra, G.O.; Moina, C.A.; Hernández, L.F.; Varela, F.E.; Vilche, J.R. Materials Science Forum 1995, 192-194, 711.

18. Moina, C.A.; Varela, F.E.; Hernández, L.F.; Ybarra, G.O.; Vilche, J.R. J. Electroanal. Chem. 1997, 427, 189.

19. Biaggio, S.R.; Bocchi, N.; Rocha-Filho, R.C.; Varela, F.E., in preparation.
20. Udupa, H.V.K.; Venkatesan, V.K.; Krishnan, M. In Standard Potentials in Aqueous Solutions; Bard, A.J.; Parsons, R.; Jordan, J., Eds.; Marcel Dekker: New York, 1985; Chapter 17, pp 526-537.

21. Grundner, M.; Halbritter, J. J. Appl. Phys. 1980, 51, 397.

22. D'Alkaine, C.V.; de Souza, L.M.M.; Nart, F.C. Corrosion Sci. 1993, 34, 117.

23. Bai, L.; Conway, B. E. J. Electrochem. Soc. 1990, 137, 3737.

24. Heusler, K.E.; Schulze, M. Electrochim. Acta 1975, 20, 237.

25. Di Quarto, F.; Piazza, S.; Sunseri, C. Ber. Bunsenges. Phys. Chem. 1987, 91, 437.

FAPESP helped in meeting the publication costs of this article 